\title{
CÓMO LEER LA BIBLIA (NO SOLO) EN TIEMPOS DE PANDEMIA
}

\author{
How to Read The Bible (not only) \\ in Times of Pandemic
}

\begin{abstract}
P. Mario Yépez Barrientos CM
Párroco de Nuestra Señora de la Asunción,en Miraflores: aeropagita@hotmail.com https://orcid.org/0000-0003-0242-7254
\end{abstract}

\section{RESUMEN}

En el presente artículo, se proponen algunas advertencias sobre una adecuada lectura del texto bíblico, puesto que, se sigue persistiendo en la interpretación fundamentalista, incluso entre católicos - y que ha cobrado fuerza en este tiempo de pandemia - que desvirtúa notoriamente el verdadero sentido de lo que afirmamos cuando decimos que la Biblia es Palabra de Dios, alejándonos de una interpretación coherente $y$, que, a su vez, pueda ayudar al debate teológico en la actualidad. Para lograr esto, en primer lugar, trataré de situar la problemática del acercamiento a los textos bíblicos de índole fundamentalista - y que resulta ser muy peligrosa y tentadora -; en un segundo apartado, presentaré algunas pautas previas para acercarnos adecuadamente a los textos bíblicos según las orientaciones del Magisterio de la Iglesia y de los avances en los estudios de las ciencias bíblicas; y finalmente, les ofreceré una opinión conclusiva acerca de la importancia de los textos de la Biblia en cuanto a su perspectiva religiosa para la lectura cotidiana de la vida de los creyentes e inclusive, para todos aquellos que deseen conocerla mejor.

\section{Palabras clave:}

Biblia, fundamentalismo, interpretación.

\begin{abstract}
In this article, I want to propose some warnings about a proper reading of the biblical text because some readers persist in the fundamentalist interpretation, even some Catholics readers - and this interpretations have been strong in pandemic times - who notoriously distorts the true meaning of what we affirm when we say that the Bible is the Word of God, moving away from a coherent interpretation and that it can help the theological debate today too. If we want to achieve this, in the first place, I will try to place the problem of the approach to biblical texts of a fundamentalist nature - and it could be very dangerous and tempting -; in the second place, I will present some preliminary guidelines to adequately approach the biblical texts according to the orientations of


the Magisterium of the Church and the advances in the studies of biblical sciences; and finally, I will offer you a conclusive opinion about the importance of the texts of the Bible in terms of your religious perspective for the daily reading in the life of believers and even for who wish to know

\section{Keywords:}

Bible, fundamentalism, interpretation.

\section{INTRODUCCIÓN}

Es posible que la Biblia sea el conjunto de libros más leídos por hombres y mujeres de todos los tiempos y culturas, pero no sé de verdad si sea, al mismo tiempo, la biblioteca mejor comprendida, porque considero que, por su carácter religioso, no es suficiente leer los textos con el afán de conocer de qué tratan, sino más bien llegar a comprender la intención del autor, al menos hasta donde se pueda, pues se cree que trasmite un mensaje que procede de Dios. La tendencia general de quienes se acercan a leer los textos bíblicos, sobre todo los que se confiesan cristianos, es hallar justamente este mensaje, pero quizá lo que aún cuesta entender, es que esto reviste una tarea titánica porque hablamos de un trabajo no solo de lectura sino de interpretación, debido a que son textos antiguos y con concepciones muy diferentes a los que se tiene hoy, $y$, por ende, no puede ser algo tan fácil de obtener. Pero, notamos que llama mucho la atención una perspectiva de lectura más fácil y segura que se obvia muchos pasos que de por sí se exigiría la lectura de la Biblia, y que no solo se mueve en los ámbitos de iglesias evangélicas o de grupos cristianos, sino también dentro de la misma Iglesia Católica, y es la perspectiva fundamentalista ${ }^{2}$. Esto obliga a advertir convenientemente del peligro que encierra y, a su vez, proponer algunos criterios previos que ayuden a alcanzar el objetivo de una interpretación adecuada y más coherente, y para ello resulta conveniente conocer las indicaciones que nos da el Magisterio de la Iglesia ${ }^{3} y$ los aportes de los estudios bíblicos desde la perspectiva de la interdisciplinariedad ${ }^{4}$.

Un primer aspecto que quiero anotar es que hay un trecho del camino que se nos ha facilitado para la interpretación del texto, que no siempre somos conscientes de su importancia, y es que tales escritos han llegado a nosotros en nuestro propio idioma, sabiendo que fueron redactados en lenguas antiguas como el hebreo, arameo y griego; y además, se ha realizado este trabajo de redacción con numerosos manuscritos de diferentes épocas intentando encontrar el posible texto

2 Hablaré al respecto en este artículo, pero los animo a leer detenidamente lo que dice Benedicto XVI en la Exhortación Postsinodal Verbum Domini en el numeral 44, sobre este estilo de lectura bíblica y puedan corroborar lo que pasaré a explicar.

3 Es importante reconocer que desde la Providentissimus Deus del Papa León XIII (1893), pasando por la Spiritus Paraclitus de Benedicto XV (1920), y la Divino Afflante Spiritu de Pío XII (1943), el Magisterio de la Iglesia fue apoyando decididamente al estudio de la Escritura con rigor científico alcanzando su culmen con la Constitución Dogmática Dei Verbum del Concilio Vaticano II (1965). A ello debemos complementar el importante documento de la Pontificia Comisión Bíblica La interpretación de la Biblia en la Iglesia (1993) y la exhortación postsinodal Verbum Domini de Benedicto XVI (2010). Para el amigo lector recomiendo vivamente la lectura de estos documentos eclesiales si desea conocer ampliamente las orientaciones del Magisterio sobre la lectura e interpretación de la Sagrada Escritura.

4 Cuando se habla de interdisciplinariedad, debemos entender que los estudios bíblicos dialogan activamente con diferentes ciencias como la sociología, arqueología, historiografía, geografía, y han aportado muchísimo al conocimiento del mundo de la Biblia, no tanto en el afán de constatar la certeza de los 
original (tarea imposible), hasta elegir finalmente, de una forma convencional, pero sustentada metodológicamente, el manuscrito más fiel al original (crítica textual), que se corresponde a la versión de las tantas que llegan a nuestras manos. Sobre esto, hay que agradecer mucho a quienes, habiendo estudiado las lenguas bíblicas, nos han ayudado enormemente con la traducción de tales escritos. Aunque, pareciera un trabajo muy simple de traducción, no se puede negar que entre muchos textos bíblicos se da el fenómeno de la interpretación premeditada, con lo cual es muy evidente que la Biblia se interpreta a sí misma5, y a esto le podemos sumar la labor de las grandes traducciones (como pasó con la traducción al griego conocida como la Septuaginta y la misma Vulgata) que también apelaron a interpretar el sentido de los vocablos, $\mathrm{y}$, posteriormente se siguió realizando esta tarea hasta nuestros días con las diferentes traducciones o versiones que han llegado a nuestras manos. Obviamente, esto no puede darse de una manera arbitraria, pero no se puede negar que, al traducir, no siempre podremos encontrar hoy términos en nuestros idiomas actuales que puedan expresar lo que aquellas palabras hebreas, arameas o griegas significaron en su tiempo (de allí la importancia de la filología y el estudio del contexto cultural).
Ahora bien, una vez acogidas tales traducciones, al iniciar la búsqueda del mensaje que Dios pueda tener preparado para el creyente, debemos purificar la idea de que los textos sean en sí mismos sagrados, intocables, definidos, e incluso atrevernos a afirmar que nosotros somos los destinatarios directos de estas obras. Aquí es donde empieza el debate de una adecuada lectura e interpretación de estos textos. No es raro que muchos han quedado escandalizados ante la aplicación de una lectura y estudio críticos de estos textos pensando que, con ello, se destruiría todo el edificio de la interpretación bíblica de muchos siglos, conduciendo a la gente a la incredulidad. Aunque no se puede negar que por mucho tiempo la Iglesia mantuvo el patrimonio de la Escritura como algo reservado para la jerarquía, llegando al pueblo de Dios los textos bíblicos solo por medio de la predicación, lo cierto es que esta misma Iglesia ha apoyado decididamente el estudio profundo de los textos bíblicos desde el s. XX, apoyados en las ciencias bíblicas y la interdisciplinariedad hasta ofrecer criterios de interpretación muy importantes teniendo como eje central la Revelación de Jesucristo. No se puede negar que sigue habiendo una tensión en esta relación a veces difícil entre el aporte de la crítica literaria y la búsqueda del mensaje divino:

hechos que se cuentan, sino en comprender mejor el contexto cultural en donde se desenvolvieron todos los que contribuyeron a la redacción de los textos bíblicos. Así podemos leer en el documento La interpretación de la Biblia en la Iglesia de la Pontificia Comisión Bíblica (1983) lo siguiente: "Para comunicarse, la Palabra de Dios se enraíza en la vida de grupos humanos (cfr. Sir 24,12), y se abre camino a través de condicionamientos psicológicos de las diversas personas que han compuesto los escritos bíblicos. Las ciencias humanas, por tanto, en particular la sociología, la antropología y la psicología, pueden contribuir a una mejor comprensión de algunos aspectos de los textos. Conviene notar, sin embargo, que existen muchas escuelas, con divergencias notables entre ellas, sobre la naturaleza misma de tales ciencias. No obstante, un buen número de exégetas ha sacado provecho recientemente de este tipo de investigaciones" (p. 53)

5 rey David en 2Sam, y trata de interpretar pasajes, para ofrecer una perspectiva diferente de situaciones comprometedoras con el personaje David. Solo para dar un ejemplo, si se lee detenidamente 2Sam 24 y luego 1Cor 21, podrá darse cuenta que se cuenta la misma historia, la del censo en tiempos de David, pero al compararlo verá que se busca menguar la responsabilidad de David, atribuyendo la decisión a una incitación del Satán y no la decisión del rey de llevar a cabo aquel censo. 
De hecho, una de las mayores enseñanzas recibidas es que resulta ingenuo pensar que una metodología es neutra. Todas parten de una hermenéutica y esta, a su vez, está anclada en una concepción de la Escritura. Es necesario, pues, que la hermenéutica bíblica reflexione sobre su propia praxis. Pues siendo la Escritura un libro de creyentes escrito para creyentes, por principio el método no puede excluir la fe (...). En coherencia con DV 11, el número 12 de la Constitución dogmática apuntaba que para una correcta hermenéutica hay que tener en cuenta, tanto la humanidad de la Escritura - y con ello, el condicionamiento del autor y del lenguaje, el uso de instrumentos y métodos científicos y de aquellos derivados de las ciencias humanas y sociales como la interpretación en el Espíritu: principio de totalidad, lectura desde la Tradición viva, analogía de la fe y actualización de la Escritura (García Fernández, 2017, p.297-298) $)^{6}$.

Esto revela un problema de fondo, el que los estudios bíblicos hayan estado siempre rondando el ámbito de la intelectualidad eclesial, a veces con connotación muy exclusivista, pero no ha podido dar el salto metodológico a las instancias más cercanas al pueblo de Dios. Quizá por un lado ciertas instancias prefirieron mantener el mismo predicamento acerca de la Biblia para no provocar supuestamente más confusión de lo que se estaba generando en el nivel de las especializaciones bíblicas como una reacción frente a los expertos en la metodología de los estudios bíblicos cuyas investigaciones solo se reducían al ámbito científico-literario. Sobre este tema, quiero recoger lo que el Papa Francisco nos ha dejado en la Carta Apostólica en forma Motu Proprio "Aperuit Illis" con la que instituyó el domingo de la Palabra de Dios (III domingo del Tiempo Ordinario):

Estas palabras contienen una gran enseñanza. La Biblia no puede ser sólo patrimonio de algunos, y mucho menos una colección de libros para unos pocos privilegiados. Pertenece, en primer lugar, al pueblo convocado para escucharla y reconocerse en esa Palabra. A menudo se dan tendencias que intentan monopolizar el texto sagrado relegándolo a ciertos círculos o grupos escogidos. No puede ser así. La Biblia es el libro del pueblo del Señor que al escucharlo pasa de la dispersión y la división a la unidad. La Palabra de Dios une a los creyentes y los convierte en un solo pueblo (Francisco, 2019, n4).

El asunto es que, en la actualidad con todo el fenómeno de la globalización y los avances en comunicaciones e informática, el problema no pasa porque no se tenga acceso a toda esta información previa (aunque hay que reconocer que hay demasiada información más no siempre la conveniente), sino más bien parece que el verdadero problema gira en torno a dos aspectos: por una parte, se ha reforzado la perspectiva canónica ${ }^{7}$ de la interpretación

6 La autora presenta en su estudio: Oyentes. La Escritura como canon de la Iglesia, dentro de la obra Revelación Tradición y Escritura de A. Del Agua (ed.), un alturado comentario sobre la relación de la comunidad de creyentes con la Palabra de Dios a partir de una adecuada comprensión del canon de los escritos de la Biblia y los efectos que eso conlleva en la hermenéutica bíblica.

7 Para un mayor conocimiento de este acercamiento canónico pueden leer La interpretación de la Biblia en la Iglesia de la PCB (p. 47-49) y para ampliar el debate propuesto el artículo el artículo de Marta García Fer- 
de los textos dejando al margen todo lo que tenga que ver con analizar el texto aplicando métodos críticos y científicos y desde otros acercamientos (no se puede negar el gran rechazo hacia el método histórico-crítico), y por otra parte, no se ha logrado adaptar con un lenguaje sencillo todo el bagaje técnico, resultando muchas veces ser tedioso estudiarlo y comprenderlo. Ante lo primero, no podemos hoy en día volver a la cerrazón de una sola vía, más bien se debería aprovechar todo lo trabajado por años y aprender a dialogar y a interactuar responsablemente con todos los métodos posibles de unos textos que rebosan tanto por ofrecer a todo ser humano que quiere mantener viva la llama de su fe, y, con respecto a lo segundo, se requiere trabajar mucho más en la transmisión y divulgación de la información haciéndola más cercana a los lectores. Al respecto, el Papa Francisco recientemente ha comentado esto en la Carta Apostólica "Scripturae Sacrae Affectus" por el XVI aniversario de la muerte de San Jerónimo:

La riqueza de las Escrituras es desafortunadamente ignorada o minimizada por muchos, porque no se les han proporcionado las bases esenciales del conocimiento. Por tanto, junto a un incremento de los estudios eclesiásticos dirigidos a sacerdotes y catequistas, que valoricen de manera más adecuada la competencia en la Sagrada Escritura, se debe promover una formación extendida a todos los cristianos, para que cada uno sea capaz de abrir el libro sagrado y extraer los frutos inestimables de sabiduría, esperanza y vida (Francisco, 2020).

Ante lo manifestado por el Papa, amerita un repensar mejor las cosas en este ámbito del estudio de la Escritura. De esta forma, creo que puede ser de interés proponerles una opinión lo más sustentada posible de un tema apasionante para quienes realmente quieren acercarse a los textos bíblicos manteniendo el deseo de hallar el mensaje de Dios, pero haciendo un camino adecuado para ello.

\section{LECTURA FUNDAMENTALISTA DE LA BIBLIA}

Muchos pretenden diferenciar desde un sentido negativo a un cristiano evangélico (denominación más usada en Latinoamérica; donde no incluiría a grandes sectores de las iglesias protestantes que muestran una preocupación seria por los estudios bíblicos) de un católico por la lectura-interpretación que hacen de la Biblia, aunque podemos llevarnos más de una sorpresa cuando en círculos católicos también se puede constatar esa misma forma de acercamiento. La característica general de esta forma de leer-interpretar los escritos de la Biblia es que se lee al pie de la letra (sentido literalista), lo que genera que cuando toman de uno y otro lado pequeños pasajes o fragmentos terminan por armar un discurso aparentemente convincente, sustentando categóricamente con la afirmación de que es la mismísima Palabra de Dios ${ }^{8}$. Obviamente, esta manera de proceder cuenta con una justificación muy concreta: estamos

nández: Oyentes. La Escritura como canon de la Iglesia (pp. 283-313) en el libro Revelación, Escritura y Tradición de Agustín Del Agua (ed.).

8 Puede ayudar para conocer más sobre la lectura fundamentalista lo que dice la PCB en La interpretación de la Biblia en la Iglesia (pp. 64-68), y un buen comentario acerca del enfoque fundamentalista de la Escritura lo podemos encontrar en el capítulo 2 de la obra de D. Witherup: "Fundamentalismo bíblico. Lo que todo católico debe saber" (pp. 18-31) 
ante un texto "sagrado", "Dios nos lo ha revelado directamente" concediéndose así la licencia para tomar de cualquier lado y construir un argumento de carácter dogmático. Sobre esto, nos ayuda esta advertencia dada por el P. Eduardo Arens en su obra "La Biblia sin mitos":

Para el fundamentalista, el texto de la Biblia es la única norma objetiva (por ser escrita) que acepta, y esa norma (la Biblia) viene de Dios mismo, quien la dictó a los escritores. Puesto que tiene a Dios como su autor. La Biblia no puede tener error alguno, incluso en materias de historia y de ciencia. Esta es la tesis fundamental sobre la que reposa toda la estructura doctrinaria del fundamentalismo (Arens, 1990, p.299)

Ahora bien, es verdad que este término fundamentalista en el común de las personas es un vocablo que causa temor, obviamente por las implicancias que conlleva su aplicación, pero sorprendentemente, tenemos que reconocer que resulta ser muy tentador seguir este tipo de lectura.

La lectura fundamentalista ofrece de modo atrayente lo que Dios nos dice en el ahora de nuestra historia colmando así el anhelado deseo de las personas a hacer lo "que Dios manda" y a evitar lo que "Dios no quiere". El problema, entonces, ya no pasa tanto porque cualquier persona que lea estos textos se sienta por sí mismo capaz de interpretar tales escritos, sino que son unos pocos los que, llevados justamente por llamadas experiencias de "iluminación" o "revelaciones particulares", confirman que lo que está escrito viene de Dios y, sorprendiendo a propios y extraños, ofrecen a sus seguidores o miembros de sus grupos o iglesias un camino seguro por donde andar, justamente a aquellos que se ven abrumados por las circunstancias que vienen afrontando, y la acogen como la única y correcta interpretación.

Si esto es así, entonces la gran afirmación de esta posición es la consideración de que la Biblia es definitivamente Palabra de Dios. Sin duda el fundamentalista lo va entender de esta única forma posible y por eso siempre repetirá este estribillo: "lo ha dicho el Señor". Pues bien, veamos lo que ha dicho el Señor.

- Les dijo Josué: "No temáis ni desmayéis; sed fuertes y tened buen ánimo, pues así hará Yahveh con todos vuestros enemigos con los que habéis de combatir". Después de esto, Josué los hirió, les dio muerte y los hizo colgar de cinco árboles, donde estuvieron colgados hasta el atardecer. Al ponerse el sol, mandó Josué que los bajaran de los árboles, que los arrojaran en la cueva donde se habian escondido y que en la boca de la cueva colocaran grandes piedras, que están alli hasta el día de hoy (Jos 10,25-27) ${ }^{9}$.

¿Puede Dios ordenar tan macabra masacre?

- A los hijos de Edom tenles, Señor, en cuenta el día de Jerusalén, cuando decian: "iDesnudadla, desnudadla, hasta sus mismos cimientos!". iCapital de Babel devastadora, bendito el que te pague como a nosotros tú has pagado! iBendito el que agarre y estrelle contra la roca a tus pequeños! (Sal 137,7-9)

¿Cómo puede ser bendito alguien que mate a niños inocentes?

9 Las citas han sido tomadas de la Castilian Bible Version (2003) del programa BibleWorks 7. 
- Si un hombre comete adulterio con la mujer de otro, ambos adúlteros morirán sin remisión. Si alguno se acuesta con la mujer de su padre, descubriendo la desnudez de su padre, los dos morirán sin remisión. Su sangre caerá sobre ellos. Si un hombre se acuesta con su nuera, ambos morirán sin remisión, porque han cometido una infamia. Su sangre caerá sobre ellos (Lv 20, 10-12).

¿Tenemos que aplicar así sin más lo que dice la Ley del Levítico?

Ante todas estas citas, ¿es posible aceptar estos pasajes de la Biblia y afirmar que esto lo ha dicho el Señor? ¿Debemos afirmar tan tajantemente que este es el querer de Dios?

Sumado a esto, otro aspecto de esta lectura fundamentalista, muy requerida en nuestro tiempo, pasa por considerar los textos bíblicos como profecías entendido como presagios sobre el futuro, anticipos de hechos que están sucediendo o sucederán pronto, con lo cual se apela a otro estribillo muy conocido: "se cumplió la Escritura". Veamos algunos ejemplos:

- Pero en aquellos días, después de aquella tribulación, el sol se oscurecerá y la luna no dará su brillo, las estrellas irán cayendo del cielo, y el mundo de los astros se desquiciará. (Mc 13,24-25).

¿Es posible que caigan las estrellas del cielo? ¿Pueden desquiciarse los astros por la sola orden de Dios?

- 18 hijitos, es la hora última. Habéis oído decir que viene un anticristo; pues bien, ahora han llegado muchos anticristos. De aquí conocemos que es la hora última $(1 \mathrm{Jn} 2,18)$.

¿Quiénes son esos anticristos? ¿Es una persona específica en la historia de la humanidad? ¿Ya llegaron o van a venir más?

Podemos sumarle a la anterior lista ciertos comentarios que se vienen divulgando con diversos textos bíblicos que supuestamente justificarían la pandemia del COVID 19, intentando asegurar que Dios ya nos lo había prevenido pues estaba en la Escritura. Así se apoyan en las famosas plagas de Egipto (Ex 7,14-12,32) para creer que Dios está repitiendo su llamada de atención como lo hiciera al faraón y a su pueblo, o, mejor aún, en las propias palabras de Jesús, anunciando a modo de predicción que iba de todas maneras a suceder un tiempo de duro sufrimiento y es justamente este que estamos viviendo (Mt 24,21-22), o mucho más convincente la profecía del Apocalipsis sobre las plagas que recaerían sobre la Babilonia, que no es sino el Perú (Ap 18,8).

Las desgracias que sobrepasan al control humano siempre han provocado el deseo de buscar su origen en el plano religioso, y quienes se apoyan en esta lectura fundamentalista encuentran en la Biblia el mejor medio para constatarlo, apelando a referencias supuestamente precisas que encierran la verdad de tales sucesos. Otra vez, camino seguro para hallar respuestas.

La pregunta más obvia ante estas cuestiones sería: ¿Somos nosotros los destinatarios de esas profecías? ¿estaban viendo estos autores el futuro de verdad? ¿qué se entiende por profecía bíblica? Aunque, pareciera evidente la respuesta, para un fundamentalista no lo es.

Para concluir esta primera parte, hay algo que resulta inevitable, y es que en los textos bíblicos existen pasajes muy difíciles de conectar con esta tendencia 
fundamentalista ${ }^{10}$. Sin embargo, de manera muy hábil, siempre se encuentran razones y justificaciones para este tipo de afirmaciones radicales, cosa que, para un lector crítico, incluso en el sentido de fe, resultaría inaudito aceptar. No han escuchado algunos comentarios como estos: "Dios es poderoso y todo lo puede hacer", "aquí el tema no es explicarlo sino creerlo sin más", "tu razón no lo puede entender", etc. Quizá amigo lector puedas agregar muchas más afirmaciones de este tipo, pero creo que es suficiente para continuar con nuestro análisis.

\section{PAUTAS PREVIAS PARA UNA ADECUADA LECTURA DE LOS TEXTOS BIBLICOS}

De entrada, no estoy pretendiendo vulnerar el concepto de que la Biblia es Palabra de Dios, lo que creo es que, para llegar a ello, hay un camino que recorrer. Así que paso a referir estas pautas necesarias a tener en cuenta:

1. Si han estado atentos, he procurado hablar de Biblia como biblioteca y no como un libro ${ }^{11}$, y es que esto no resulta ser tan fehaciente como parece. Cada escrito de la Biblia tiene su propia historia. Ninguno de los autores (quienquiera que sean) pretendió que su obra estuviese ubicada al lado de la otra. Incluso, notamos que en el proceso de formación de cada texto no fueron obras cerradas por el posible autor original, sino que incluso se fueron añadiendo elementos de interpretación hasta que ante la propuesta del redactor final se convino en un proceso de canonización donde intervino la comunidad creyente que definió su carácter de inspirado por Dios $^{12}$, y como tal, capaz de transmitir el mensaje de Dios en orden a la salvación de los hombres. Por eso, no se puede construir pensamientos tomando de uno u otro lado y armar un discurso y terminar diciendo: "esto es Palabra de Dios". Al final, hace uno decir a Dios lo que a uno le parece y esto es peligroso.

Entendemos que en la Biblia encontramos la Revelación de Dios hecha escritura, pero Dios se revela en la historia, no en los textos en sí mismos y abarca mucho más que la propia Escritura. Si esto es así, no podemos pretender hallar en la Biblia la total manifestación de quién es Dios, sino la comprensión que el hombre ha tenido en su contexto histórico-cultural a lo largo de muchos siglos de historia. Esto prueba las diversas maneras de comprender a Dios, de acuerdo a como los autores intentaron presentarlo, motivado por sus propios interrogantes y con las limitaciones propias de sus marcos culturales. No debemos olvidar que la dinámica de la fe parte de la vida, no de un texto.

10 Sobre esto hay una gran cantidad de textos, pero solo para poner un ejemplo, pueden leer Jos 10,12-13. ¿Saben lo que implicaría entender el pie de la letra esta afirmación? ¿Creen que sería suficiente decir que Dios todo lo puede y, claro que podría suceder?

11 La palabra "biblia" propiamente es un vocablo griego plural, que significa "libros"; que se latinizó y luego pasó al castellano. Por tanto, no es un libro, sino un conjunto de libros.

12 Se conoce como "canon" a la lista de textos que se consideran inspirados por Dios y con un carácter normativo para la Iglesia Católica (AT y NT), y fue un proceso que duró mucho tiempo entre el s. II y el IV d.C. Obviamente, debemos distinguirlo del canon de la Biblia Hebrea (fines del s. I y s. II d.C.). Además, debemos tener presente que en el marco de la historia del cristianismo se aceptaron los libros deuterocanónicos, siete textos hallados en griego con lo que se completó el AT tomado de la versión Septuaginta, traducida luego a la Vulgata, los cuales la Iglesia católica consideró también como libros inspirados, diferenciándose así de la versión que asumió el protestantismo (Reina-Valera y otras) que no los aceptó. De allí que tengan 7 libros menos: Tb; Jud, Bar; 1 y 2 Mac; Eclo, Sb, además de algunos fragmentos griegos de Dn y de Est. El Concilio de Trento en 1546 declaró como canónica la Vulgata, que incluía los deuterocanónicos y los añadidos griegos de Est y Dn. Para una mayor profundización se puede leer del P. Arens, La Biblia sin mitos (pp. 99-123). 
Ahora bien, los cristianos creemos que Jesucristo nos ha presentado a Dios como Padre, convirtiéndose, sin duda, en un paradigma de confrontación con las diversas maneras de comprender en el Antiguo Testamento (AT) ${ }^{13}$, pero también no debemos olvidar que la propia comunidad cristiana en sus diversas maneras de comprender a Jesús, también fueron recogiendo sus testimonios adecuándolos a su contexto cultural y a sus propias interrogantes ${ }^{14}$.

No podemos decir sin más que tales escritos son Palabra de Dios y justificar con ella lo que queramos; no lo creo correcto, parece más bien una "traición al texto".

2. Al comprender este primer aspecto, tenemos que reconocer entonces que estamos ante muchos años de producción literaria circunscrita a un horizonte cultural muy amplio y, sin duda, muy lejano a nosotros. Cuidado con la afirmación "es Palabra de Dios para todos los tiempos". También esto necesita una explicación.

\section{Si queremos comprender bien} los textos de la Biblia debemos tener un mínimo de conocimiento acerca del mundo en el que estos textos se produjeron. Tampoco resulta suficiente hablar solo de Israel, personaje central y a su vez destinatario en la obra del AT, aunque su influencia continúa en el Nuevo Testamento (NT), sino necesitamos saber del entorno en el que fue forjando su identidad (cultura de Oriente Próximo: Egipto, Canaán, Mesopotamia). Existe hoy una gran reivindicación de los valores culturales de los pueblos de la humanidad, y eso también debe aplicarse a la interacción de los pueblos en la antigüedad con Israel. Muchas veces se piensa que la civilización occidental fue la más avanzada, y dejamos al margen las diversas manifestaciones culturales que conformaron la extraordinaria civilización oriental. Obviamente, que el horizonte cultural grecorromano fue determinante en la configuración del NT, pero no se puede pretender que los autores pensasen como helenos, aun utilizando los vocablos del griego koiné, porque en el tiempo de la redacción del NT todavía estaba muy fuerte la influencia del judaísmo plural de las primeras generaciones de cristianos $^{15}$. Hablar del mundo oriental y antiguo es conocer esquemas distintos de pensamiento, de cómo entender la vida, y, en definitiva, cómo comprender a la divinidad, pero todas válidas dentro de los parámetros propios de la investigación científica. El ofrecimiento de información de muchas versiones o traducciones de las Biblias modernas sobre cada escrito en sus introducciones, pies de páginas,

13 Nos recuerda la DV 16: "Dios, pues, inspirador y autor de ambos Testamentos, dispuso las cosas tan sabiamente que el Nuevo Testamento está latente en el Antiguo y el Antiguo está patente en el Nuevo. Porque, aunque Cristo fundó el Nuevo Testamento en su sangre, no obstante, los libros del Antiguo Testamento recibidos íntegramente en la proclamación evangélica, adquieren y manifiestan su plena significación en el Nuevo Testamento, ilustrándolo y explicándolo al mismo tiempo".

14 El mismo canon del NT refleja un cristianismo plural, pues tenemos cuatro versiones sobre Jesucristo, y aunque guardan un esquema similar, son notorias sus peculiaridades y diferencias. Los mismo el cuerpo epistolar, con matices diferentes entre las cartas paulinas y las demás. A eso debemos sumar las incongruencias entre lo que narra Hechos de los apóstoles y las cartas de Pablo sobre los comienzos de la primitiva comunidad cristiana. Esto evidencia que los propios seguidores de Jesús en el lapso de la primera y segunda generación de cristianos poseían una perspectiva de comprensión acerca del acontecimiento Jesucristo, aunque todos confesaban que era el enviado de Dios Padre, su Hijo, para salvar a los hombres del pecado con su muerte y resurrección. Para una mayor profundización pueden leer el cap. 1, "El proceso de surgimiento del cristianismo" de Rafael Aguirre en su obra Así empezó el cristianismo (pp. 12-48).

15 Gracias a la interdisciplinariedad, sabemos que el judaísmo del tiempo llamado inter-testamentario, era muy plural, aunque contaban con elementos identitarios muy bien definidos (los que se fueron forjando 
citación externa de citas, son elementos que para un lector serio resultan útiles para una adecuada interpretación. Estos textos tienen un horizonte cultural donde se han gestado y ayudan mucho a comprender lo que intentaron comunicar a sus destinatarios originales (aunque no siempre tengamos todos los códigos en el mismo texto). Un mínimo de conocimiento ayudaría mucho a alejarnos de lecturas fundamentalistas que sortean enormemente esto y abrirán nuevas perspectivas de reflexión puesto que las preguntas que se hicieron los hombres de antaño nos las seguimos haciendo hoy nosotros.

3. Otro factor importante para una buena lectura de los textos bíblicos es conocer y distinguir los géneros literarios.

Para descubrir la intención de los hagiógrafos, entre otras cosas hay que atender a "los géneros literarios". Puesto que la verdad se propone y se expresa de maneras diversas en los textos de diverso género: histórico, profético, poético o en otros géneros literarios. Conviene, además, que el intérprete investigue el sentido que intentó expresar y expresó el hagiógrafo en cada circunstancia según la condición de su tiempo y de su cultura, según los géneros literarios usados en su época. Pues para entender rectamente lo que el autor sagrado quiso afirmar en sus escritos, hay que atender cuidadosamente tanto a las formas nativas usadas de pensar, de hablar o de narrar vigentes en los tiempos del hagiógrafo, como a las que en aquella época solían usarse en el trato mutuo de los hombres (C. Vaticano II, Dei Verbum, $\mathrm{n}^{\circ} 12$ ).

Quienes rebaten la atención a este tema lo hacen por dos motivos: no se puede aplicar criterios de lectura crítica a un texto sagrado, y aquellos hombres de la antigüedad no conocían de ese término. Es verdad, que la consideración técnica como hoy la conocemos no se conocía, pero en la antigüedad claro que sabían utilizar convenientemente los estilos diversos de comunicación que tenían a su alcance, y siendo literatura es posible aplicar un estudio crítico al respecto. Cuando alguien desea comunicar algo a otra persona o un colectivo, debe buscar la mejor manera de hacerlo para que se logre entender el mensaje que se desea transmitir. Por tanto, un género literario en la Biblia es la manera formal como el autor buscó ofrecer el mensaje central a sus destinatarios. Cuando un emisor desea comunicar algo (mensaje) a un receptor necesita valorar el mejor medio para transmitirlo (canal); pues este último resulta ser el género literario.

El modo que utiliza el autor responde a las características no solo de quien lo recibe sino de acuerdo al mejor medio para transmitirlo. Si uno quiere compartir una receta de comida, no va a hacer un ensayo sobre el plato de comida, sino el esquema clásico de un recetario. Si quieres comunicar de una manera más sencilla, pero de forma amena una enseñanza, muchos apelan a pequeñas historias y fábulas

después del exilio, s. VI a.C.). Esto supuso que, si bien es cierto, las obras de lo que conocemos como NT se escribieron en griego, mantenía aun las categorías judías de pensamiento, su manera de concebir la fe y la vida. El horizonte cultural para las primeras comunidades cristianas seguía siendo el judío, aunque notamos ya cierta influencia del mundo grecorromano. Esto llevó a un replanteamiento en la exegesis de ciertas concepciones tomadas de la Biblia que se entendieron por algún tiempo con categorías filosóficas griegas como el caso del evangelio de Juan, las cartas de Pablo y también el Apocalipsis del NT. 
que expresan la realidad, aunque son netamente ficciones. Y así podemos multiplicar ejemplos.

Pues bien, en la Biblia encontramos diferentes géneros literarios, formas de expresión que los autores usaron para comunicar su mensaje. Puede que muchos de los géneros que hoy conocemos no lo conocían los autores del pasado, pero muchos de ellos estaban muy bien agrupados como, por ejemplo: proverbios, historia, profecía. La capacidad de distinguirlos, gracias a los estudios modernos, nos han ayudado a entender mejor las razones de tales agrupaciones, y así hemos podido comprender la riqueza literaria de los textos bíblicos que lograron conjugar mitos, leyendas, sagas, epopeyas, códigos legales, lírica, historias ejemplares, apocalipsis, evangelios, epístolas, hechos, etc.

De hecho, uno de los graves problemas del fundamentalismo y de la lectura literalista es que, ya sea simple y llanamente ignora todo lo que eso implica, o reduce los géneros literarios existentes en la Biblia a unos pocos, especialmente al histórico, de modo que todo lo toman al pie de la letra, confundiendo los géneros leyenda, mito e historia y reduciéndolos a historia; profecía y apocalíptica, reduciéndolos a vaticinios sobre el futuro; legislación y exhortación; etc. Leen la Biblia como leen las noticias e informaciones de los periódicos (Arens, 1990, p.72).

4. Continuando con los géneros literarios, no es suficiente saber de esa diferenciación sino comprender su correcta valoración para la interpretación. Uno de los parámetros de considerar la Biblia como Palabra de Dios en el estilo fundamentalista es que todo lo que se escribió sucedió tal cual. Muchos pensamos lo mismo, porque consideramos literariamente "historia" con "realidad fáctica". Quiero tocar solo dos puntos a considerar. En primer lugar, el mundo antiguo aceptaba el lenguaje mitológico y legendario y lo integraba de una forma tal a la lectura de su historia sin mayores complicaciones; de allí que aprovechaban todo ese material para las futuras reinterpretaciones que fueron dándose en los mismos escritos bíblicos. En segundo lugar, es evidente que la descripción de los mitos y las leyendas se correspondían a ciertos patrones que no muestran su preocupación en contar que tales hechos sucedieron, sino en responder a sus interrogantes actuales proyectándolos hacia el pasado con una carga simbólica buscando la significación de tales historias. Por tanto, uno de los grandes errores al acercarnos a los textos bíblicos es proponerles preguntas equivocadas.

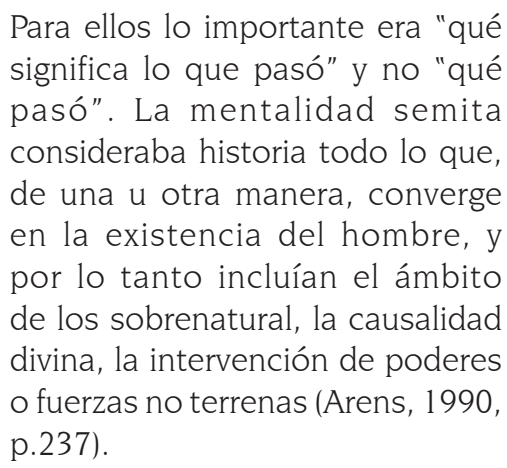

Como podemos apreciar no debemos partir con preguntas como: ¿es verdad lo que cuentas? ¿Así sucedió? ¿Lo que se narra aquí pasó tal cual? La pregunta que se debe hacer al texto es: ¿qué significa lo que nos estás contando? ¿cuál es el sentido de que describas estos hechos así? Como vemos, el problema está en la manera cómo preguntamos al texto, y, 
por ende, al autor, y no tanto al texto en sí mismo buscando que nos confirme que fueron hechos reales. Debemos romper con el esquema clásico: hechos reales - escritos bíblicos - verdad - Palabra de Dios. Esta es la deducción de los fundamentalistas ${ }^{16}$.

Hablar sobre el significado de lo que narran los escritos bíblicos es toda una tarea. Las ficciones o demás historias, aunque pueden ser historias no reales, manifiestan experiencias humanas en las que el lector puede sentirse identificado, y, por tanto, expresan una verdad, quizá no histórica, pero sí existencial.

A veces se olvida que el lenguaje simbólico ${ }^{17}$ es también comunicación de circunstancias reales, lo usamos mucho en la actualidad y sabemos que se puede entender plenamente el mensaje que deseamos transmitir. ¿Por qué no creer que los autores también se valieron de este tipo de lenguaje si también comunican verdades muy profundas? Por otro lado, muchas de las narraciones no concluyen con moralejas ni supuestas respuestas evidentes a todos los problemas que afectan al ser humano, sino que dejan abiertas más preguntas para continuar con el discernimiento. En algún momento, estos autores, decidieron plasmar por escrito esas experiencias humanas de confrontación con lo divino pues entendieron que en ellas Dios se estaba manifestando. La formulación, si se quiere teológica, que asumieron la pusieron por escrito ante nuevas interrogantes dejándonos un conjunto extraordinario de vivencias en las que Dios habla y puede seguir hablando hoy porque tales preguntas nos las seguimos haciendo en la actualidad.

5. Los escritos tienen un destinatario concreto, no somos nosotros los primeros destinatarios de los textos bíblicos. Por ello, no es posible acercarse a los textos pensando que fueron escritos para el siglo XXI, o incluso, como bien he mencionado, nos está anticipando cosas futuras que han de suceder. Por ello es importante en el estudio bíblico una metódica exegesis.

Habiendo, pues, hablando Dios en la Sagrada Escritura por hombres y a la manera humana, para que el intérprete de la Sagrada Escritura comprenda lo que Él quiso comunicarnos, debe investigar con atención lo que pretendieron expresar realmente los hagiógrafos y plugo a Dios manifestar con las palabras de ellos (C. Vaticano II, Dei Verbum, n¹2).

Los textos fueron escritos para un tiempo determinado, en una cultura determinada y para personajes concretos. Por eso es que muchas veces nos cuesta comprenderlos, porque aquellos destinatarios tenían las claves para comprender mucho de lo que los remitentes les transmitieron. Si nosotros fuéramos los destinatarios directos entonces claro que deberíamos suponer que lo que está allí escrito se

16 Puede ayudar la crítica al fundamentalismo biblicista que comenta el P. Eduardo Arens en su artículo "¿Entiendes lo que lees?" (Hch 8,30). La Biblia entre la Ilustración y el Fundamentalismo, en Cuaderno de Teología Deusto, 35, de la cual rescato a continuación algunas ideas: "El pilar, que a la vez es el talón de Aquiles del fundamentalismo biblicista es la inerrancia bíblica (...) Sin embargo, el fundamentalista descarta la dimensión histórica de la Biblia como tal, pues los cuestionamientos que desde esa perspectiva plantean los estudios críticos de la Biblia amenaza la seguridad de su edificación, razón por la cual se concentra en la inerrancia del texto - no de la historia bíblica" (pp. 38-41)

17 Sobre este tema aconsejo revisar lo dicho en el ítem sobre el lenguaje no-literal, por el P. Arens y P. Díaz Mateos, en su obra Apocalipsis, la fuerza de la esperanza (pp. 33-43). 
cumplirá. Este es otro de los pilares del fundamentalismo, y claramente inaceptable.

Un ejemplo claro es el desconocimiento del género apocalíptico, pues se empieza a creer que tales descripciones simbólicas sucederán tal cual se narran y tales personificaciones invitan a identificarlos en la realidad histórica actual, con lo cual se busca infundir terror llevándote a una reacción sumisa a la voluntad divina. Todo esto resulta una manipulación de conciencias que causa admiración e indignación por cómo se comunican estas cosas tan resueltamente. Es evidente, que la desesperación de las personas, la incertidumbre de circunstancias ajenas a veces a nuestra propia libertad (catástrofes enfermedades, plagas), provocan respuestas prontas y seguras; generando una gran aceptación de esta lectura fundamentalista, pero no pude continuar aceptándose esa forma tan espeluznante de presentar la vida religiosa y en definitiva a Dios. La apocalíptica tiene su cometido, es un libro simbólico cargado de esperanza para los que entienden su vida como una lucha constante para ser fieles a su convicción de ser discípulos de Cristo en un mundo muchas veces hostil. No podemos seguir utilizando los escritos de la Biblia para infundir temor, porque para eso no fueron escritos.

Ahora bien, claro que entendemos que, por ser Palabra de Dios, tiene un mensaje que sí puede trascender el tiempo y las culturas, pero esto no debería hacernos perder de vista que nosotros no somo los destinatarios directos sino indirectos. Nosotros como los hombres y mujeres del pasado nos confrontamos con las mismas realidades humanas, los mismos interrogantes, los mismos sentimientos, y es evidente que puede decirnos mucho los textos bíblicos hoy, pero respetando este camino propuesto. Al vernos identificados con los relatos podremos entender mejor el mensaje en vez de distanciarnos del texto con prejuicios y presupuestos absolutistas y excluyentes a todo lo que hemos compartido en este artículo.

\section{CONCLUSIONES}

La Escritura es un don extraordinario de Dios para el hombre, pero que brotó de su interacción con este mismo ser humano, quien infundido por esta gracia particular interpretó diversos acontecimientos y comprendió que Dios se revelaba todo de sí, formulando desde sus capacidades y dentro de las limitaciones culturales y temporales, diversas obras con estilos peculiares (géneros literarios) para comunicar el mensaje de salvación a sus respectivos destinatarios. Tales experiencias respondieron a diversas interrogantes que, así como en el pasado, hoy nos seguimos preguntando en nuestra relación con Dios, con el mundo, con los hombres, y por ello, la Escritura puede seguir hablándonos hoy, e iluminando nuestras decisiones y acciones. Una vez más recordamos lo que nos dijo el Papa Francisco en Aperuit illis:

Para alcanzar esa finalidad salvífica, la Sagrada Escritura bajo la acción del Espíritu Santo transforma en Palabra de Dios la palabra de los hombres escrita de manera humana (cf. Const. dogm. Dei Verbum, 12). El papel del Espíritu Santo en la Sagrada Escritura es fundamental. Sin su acción, el riesgo de permanecer encerrados en el mero texto escrito estaría siempre presente, facilitando una interpretación fundamentalista, de la que es necesario alejarse para 
no traicionar el carácter inspirado, dinámico y espiritual que el texto sagrado posee. Como recuerda el Apóstol: «La letra mata, mientras que el Espíritu da vida) (2 Co 3,6). El Espíritu Santo, por tanto, transforma la Sagrada Escritura en Palabra viva de Dios, vivida y transmitida en la fe de su pueblo santo (Francisco, 2020, n 9).

No renuncio a la lectura creyente, pero no concibo despreciar el esfuerzo que se ha venido haciendo para conocer mejor cómo acercarnos coherentemente a leer estos extraordinarios libros y, pero, aún, utilizarlos como herramientas para dogmatismos y fundamentalismos sin sentido.

Obviamente, no se puede agotar un tema tan interesante y actual con este artículo, pero creo que, con lo expresado aquí, al menos, podamos advertirnos antes de volver a afirmar que la Biblia es Palabra de Dios e ilustrar convenientemente el verdadero sentido de esta afirmación. Finalmente, claro que se puede releer los escritos de la Biblia en el contexto de esta pandemia que estamos afrontando, puesto que es una experiencia que ha vivido constantemente el ser humano de todos los tiempos, pero quizá necesitemos hacer las preguntas más convenientes al texto y no las que habitualmente hacemos, y que nos salvará de caer en pronunciamientos fundamentalistas o en dejarnos sorprender por supuestas interpretaciones cargadas de sensacionalismos emocionales que solo generan temor o repulsa.

\section{REFERENCIAS}

Aguirre R. (ed.) (2010) Así empezó el cristianismo. Verbo divino.

Arens E. (1990) La Biblia sin mitos. Paulinas.

(2008) "¿Entiendes lo que lees? (Hch 8,30). La Biblia, entre la Ilustración y el Fundamentalismo". En Cuadernos de Teología Deusto 35, pp. 29-49.

y Díaz Mateos M. (2000) Apocalipsis, la fuerza de la esperanza. CEP.

Benedicto XVI (1965) Verbum Domini. Recuperado por:http://www. vatican.va/content/benedict-xvi/es/ apost_exhortations/documents/ hf_ben-xvi_exh_20100930_ verbum-domini.html

Concilio Vaticano II (1965) Dei Verbum. Recuperado por: http://www. vatican.va/archive/hist_councils/ ii_vatican_council/documents/vatii_const__19651118_dei-verbum_ sp.html

Francisco (2020) Scripturae Sacrae Affectus. Recuperado de: http://www. vatican.va/content/francesco/es/ apost_letters/documents/papafrancesco-lettera-ap_20200930 scripturae-sacrae-affectus.html

Francisco (2019) Aperuit Illis. Recuperado de: http://www. vatican.va/content/francesco/ es/motu_proprio/documents/ p a p a - francesco-motu proprio-20190930_aperuit-illis. html 
Del Agua A. (ed.) (2017) Revelación, Tradición y Escritura, BAC.

Pontifica Comisión Bíblica (1993) La interpretación de la Biblia en la Iglesia. Salesiana, Paulinas, San Pablo.

Witherup D. (2009) Fundamentalismo bíblico. Lo que todo católico debe saber. Liturgical Press.

Fecha de recepción: 30-10-2020 Fecha de aceptación: 15-11-2020 